\title{
Sea Level Variability and Semiannual Rossby Waves in the South Atlantic Subtropical Gyre
}

\author{
P.-Y. LE TRAON \\ Collecte Localisation Satellites, Space Oceanography Group, Toulouse, France
}

\section{J.-F. MinSTER}

Unité Mixte de Recherche 39, Groupe de Recherche en Géodésie Spatiale, Toulouse, France

\begin{abstract}
We derived the sea level variability in the South Atlantic subtropical gyre between $15^{\circ}$ and $35^{\circ} \mathrm{S}$ from 2 years of the Geosat exact repeat mission altimeter data. On the mesoscale, along-track wavenumber spectra are those of nonlinear dynamics with a steeper slope and stronger energy along the eastern boundary. Frequency/wavenumber spectra reveal a significant semiannual signal at a wavelength of about $500 \mathrm{~km}$. West of the Walvis ridge $\left(5^{\circ} \mathrm{E}\right)$, this signal appears to correspond to semiannual Rossby waves of 2- to $3-\mathrm{cm}$ amplitude, propagating westward at $3 \mathrm{~cm} \mathrm{~s}^{-1}$, and showing latitude refraction effects. The pattern is very similar to that of annual Rossby waves as modeled by Reason et al. (1987). These waves are probably related to the semiannual wind component. However, understanding the exact mechanism for their excitation requires dynamical modeling. The large-scale variability also shows a significant semiannual component (about $6-\mathrm{cm}$ amplitude and $15 \%$ of the yearly variance) in phase with climatological winds.
\end{abstract}

\section{INTRODUCTION}

Geosat satellite altimeter data have been proven a very powerful tool for observing ocean mesoscale circulation [Cheney et al., 1987, 1991]. They provide quantitative estimations of the variability or synoptic maps, and also higher order statistics, such as wavenumber spectra, autocorrelation functions, and frequency-wavenumber spectra [e.g., Zlotnicki et al., 1989; Fu and Zlotnicki, 1989; De Mey and Ménard, 1989; Sandwell and Zhang, 1989; Le Traon et al., 1990; Le Traon, 1991; Stammer and Böning, 1992]. Because the Geosat satellite orbit is not accurate enough, relatively little work has been done on the large-scale signals except in tropical areas. However, time series of large-scale variability maps have been constructed [e.g., Wunsch, 1991a].

In the North Atlantic Ocean, statistical analyses of the mesoscale signal have been done quite systematically. Wavenumber spectra show complex variations with respect to latitude (related to the Rossby radius of deformation) and longitude (depending on the dynamical regime) [see Le Traon et al., 1990]. In the frequency-wavenumber domain the so-called eddy variability dominates, with wavelengths ranging between 200 and $500 \mathrm{~km}$ and with periods smaller than 150 days, but significant seasonal variability is also observed [Le Traon, 1991]. As for the large-scale signal, it appears to vary nearly in phase with the large-scale wind signal [Wunsch, 1991b].

Elsewhere in the ocean, except for root-mean-square (rms) variability studies [Zlotnicki et al., 1989; Sandwell and Zhang, 1989], these mesoscale statistics have not been analyzed systematically. This paper concentrates on the South Atlantic subtropical gyre, between $15^{\circ} \mathrm{S}$ and $35^{\circ} \mathrm{S}$, using the first 2 years of the Geosat exact repeat mission data. A similar analysis has been done for the Confluence

Copyright 1993 by the American Geophysical Union.

Paper number $93 \mathrm{JC} 00456$.

0148-0227/93/93JC-00456\$05.00 area between the Malvinas and the Brazil currents [Provost and Le Traon, 1993]. Comparison with the North Atlantic Ocean is expected to illustrate better the factors which control mesoscale variability. It has already been shown that mesoscale eddies cross the south Atlantic northwestward, from the tip of Africa to the coast of Brazil [Gordon and Haxby, 1990; Wakker et al., 1990]; they are thought to transport significant amounts of warm water from the Agulhas current into the Atlantic. The rms variability also seems slightly larger during the northern winter, contrary to conventional wisdom [Zlotnicki et al., 1989]. We will first analyze systematically the statistical properties of the mesoscale variability. In section 3 the semiannual signal will be separated and its properties compared with those for semiannual Rossby waves. Time series of the large-scale variability signal as extracted by Wunsch $[1991 a, b]$ from the same data are analyzed in Appendix B.

\section{Statistical Properties of the Mesoscale Signal}

We start by describing the mesoscale signal, i.e., maps of the rms and 17-day decorrelation, along-track wavenumber spectra, frequency-wavenumber spectra, and pseudodispersion relations. The latter will be calculated in four domains of $15^{\circ}$ longitude, labeled 21-24 (Figure 1). All properties have been estimated for 1987 and 1988 as well as separately for the winter and summer seasons. The extraction and processing of the sea level anomalies (SLA) are described in Appendix A and in Le Traon et al. [1990] and Le Traon [1991].

\subsection{Variability Maps}

The SLA variability map (Figure 2) has two maxima of up to $15 \mathrm{~cm}$ rms near the boundaries: the Brazil current in the west and the Benguela current in the east. In the central part of the basin the signal steadily increases southward from 3 to $6 \mathrm{~cm} \mathrm{rms}$. The variance of the mesoscale geostrophic velocity varies from $150 \mathrm{~cm}^{2} \mathrm{~s}^{-2}$ in the central part to $950 \mathrm{~cm}^{2} \mathrm{~s}^{-2}$ in the two energetic areas (not shown). As is now well 


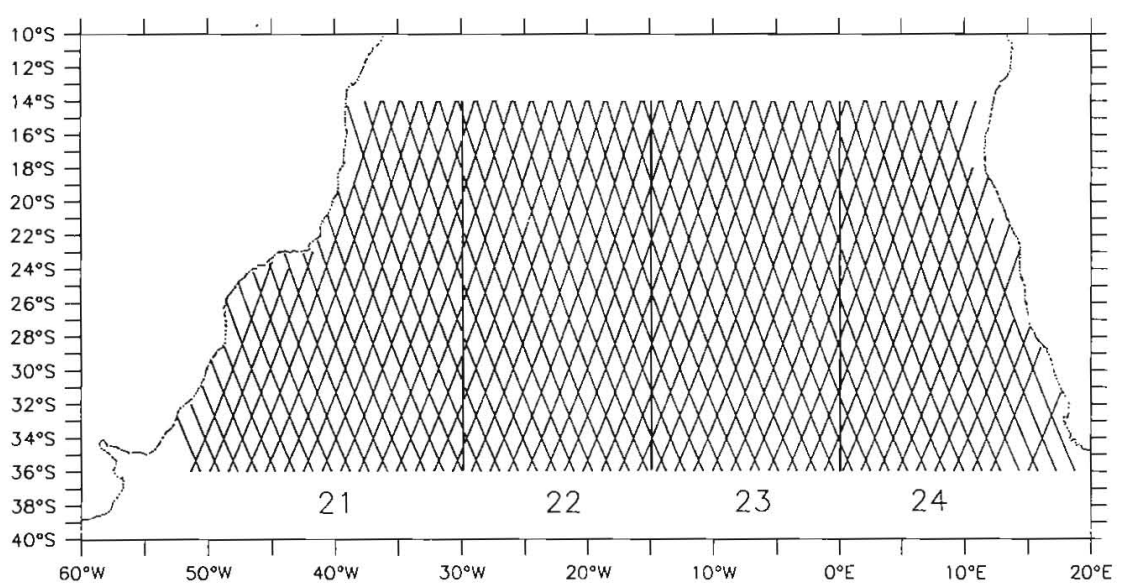

Fig. 1. The study area, in the South Atlantic subtropical gyre between $35^{\circ} \mathrm{S}$ and $15^{\circ} \mathrm{S}$, where Geosat tracks are overlaid. The two-digit numbers correspond to groups of $20^{\circ}$ (latitude) $\times 15^{\circ}$ (longitude) bins, where wavenumber and frequency-wavenumber spectra were systematically calculated.

established [e.g., Sandwell and Zhang, 1989; Chelton et al., $1990]$, there is a clear bathymetric control over the mesoscale variability (Figure 3 ).

The values agree with those of Zlotnicki et al. [1989] and Chelton et al. [1990] for the height variability, and with those of Gordon and Haxby [1990] for the geostrophic velocity (the data were processed slightly differently in the two cases). The geostrophic velocities are also comparable with those derived from surface floats, though slightly smaller (by 25\%) [Daniault and Ménard, 1985; Paterson, 1985; Piola et al., 1987]. However, few floats were deployed in the South Atlantic gyre during the First Global GARP Experiment (FGGE), so the estimation error due to sampling exceeds $20 \%$.

Figure 4 shows the isocorrelation lines of the SLA signal at a 17-day interval. In energetic areas the correlation is quite low, particularly along the Brazil current. In the central part it increases to the south, with values exceeding $50 \%$ between $30^{\circ} \mathrm{S}$ and $35^{\circ} \mathrm{S}$. Indeed, we will see later that there is significant annual variability in this area. The correlation is slightly higher on the mid-Atlantic ridge (near $20^{\circ} \mathrm{S}-15^{\circ} \mathrm{W}$ ) and isolines follow the Walvis ridge (near $25^{\circ} \mathrm{S}-5^{\circ} \mathrm{E}$ ). These patterns are similar to those for the North Atlantic [ Le Traon, 1991].

\subsection{Wavenumber Spectra}

Figure 5 gives the mean along-track wavenumber spectra for the four domains. They show the now classic threesegment pattern. Below $100-\mathrm{km}$ wavelength they are flat and indicate the measurement noise level $(3-4 \mathrm{~cm})$. Between 100 and $500-600 \mathrm{~km}$ they have steep slopes ranging from -3 (for area 21) to -4 (for area 24); we will call this part the turbulent domain. For longer wavelengths the spectra are less steep and even flat in area 24. As the track length was $3000 \mathrm{~km}$, the break at long wavelengths is well defined, particularly in area 22 . The break is at about $500 \mathrm{~km}$, which is twice the wavelength of the first internal Rossby radius [Houry et al., 1987]. The Geosat signal is more energetic at all wavelengths than the wet tropospheric correction signal deduced from the special sensor microwave imager data (see spectra in Minster et al. [1992]). Therefore we do not expect

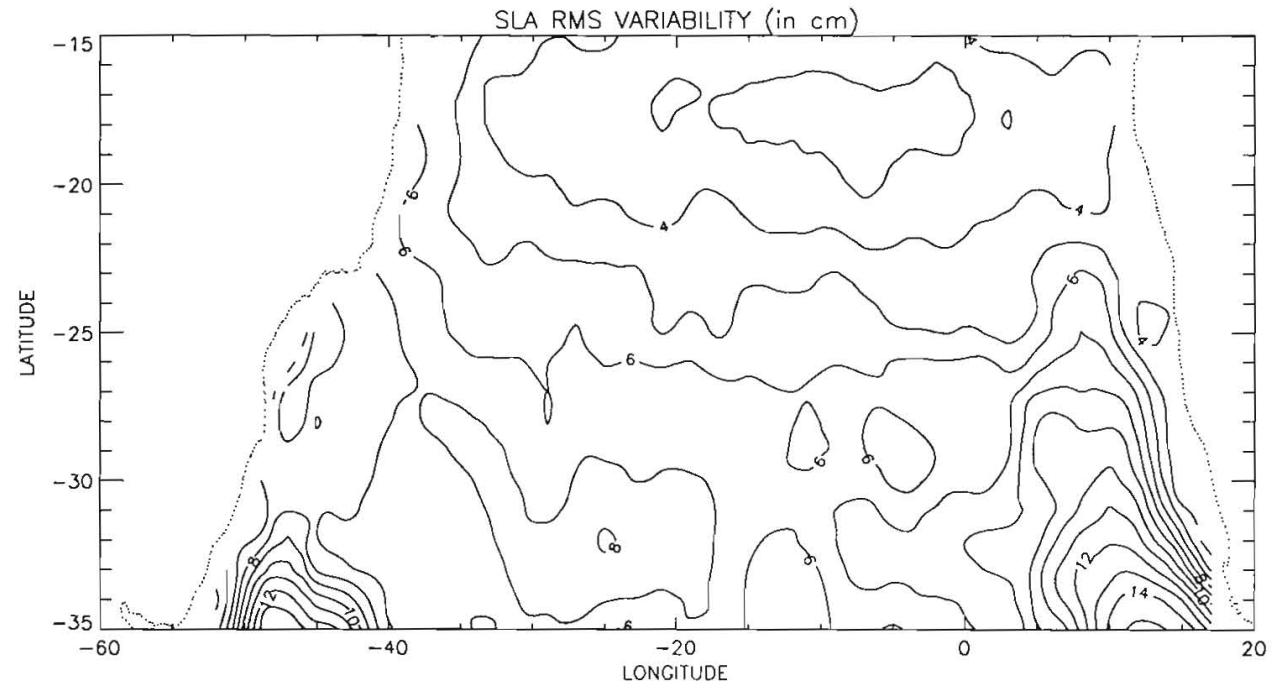

Fig. 2. The rms variability of sea level anomaly obtained from 2 years of Geosat data. Contour interval is $1 \mathrm{~cm}$. 


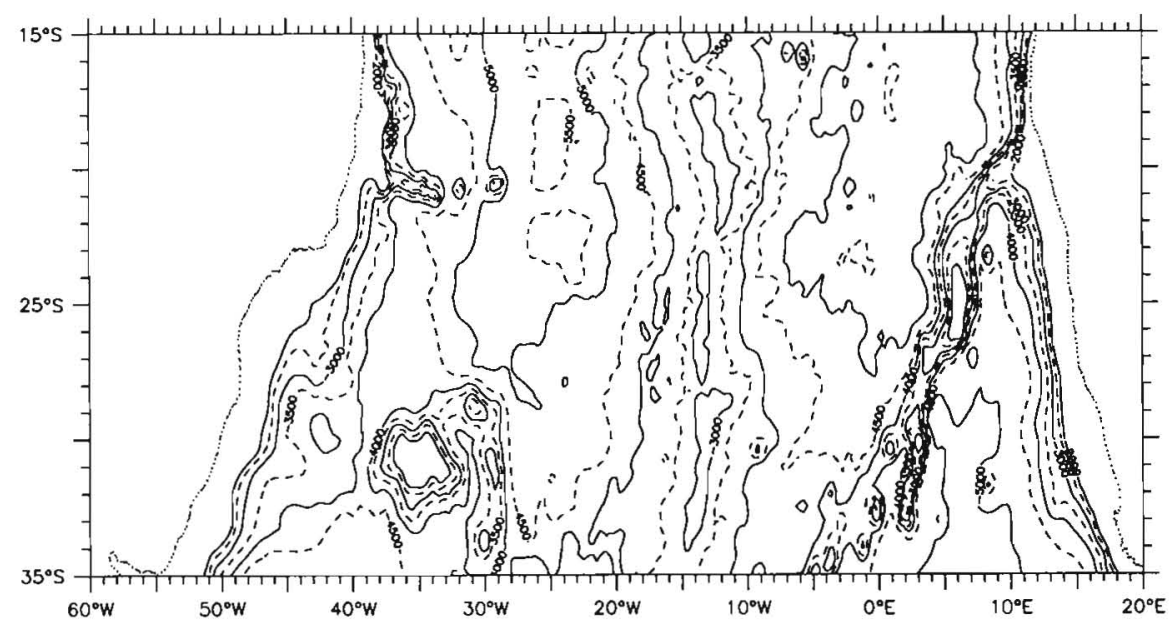

Fig. 3. Bathymetry of the study area. Contour interval is $500 \mathrm{~m}$.

our results to be affected by the inaccuracy of this correction.

The area 24 spectrum is the most energetic at all wavelengths, and particularly near $500 \mathrm{~km}$; its slope is very steep, in agreement with models for strongly nonlinear dynamics. On the contrary, the spectrum for area 21 , the other area with strong variability, is not very different from spectra for areas 22 and 23 , probably because the strong variability is only encountered in the southern border of the area and only the longer tracks are analyzed. As already noted by Stammer and Böning [1992], spectra such as in Figure 5 were only found at higher than $30^{\circ}$ latitude in the North Atlantic, that is, $10^{\circ}$ further from the equator than in the South Atlantic. This suggests that circulation in the South Atlantic gyre is more energetic and less linear than in the North Atlantic between $15^{\circ} \mathrm{N}$ and $30^{\circ} \mathrm{N}$ (see the discussion by Le Traon et al. [1990]).

In Figure 6, spectra for ascending and descending tracks of area 22 are separated. They are identical in the turbulent domain (suggesting an isotropic signal) but different at longer wavelengths: the spectrum for descending tracks (northeast to southwest) is more energetic than that for ascending tracks. Below we discuss how this relates to the semiannual signal.

\subsection{Frequency/Wavenumber Spectra}

Figure 7 shows the total frequency/wavenumber spectra for the four areas, for wavelengths between 100 and $3000 \mathrm{~km}$ and periods between 34 days and 2 years. These spectra are in variance preserving form.

In the Brazil current (area 21), energy is found near $500 \mathrm{~km}$ and 130 days, and for longer wavelengths (more than $900 \mathrm{~km}$ ) and periods of 130-200 days. A strong signal is, of course, found at the shortest periods and all wavelengths up to 2000 $\mathrm{km}$. The spectra for areas 22 and 23 are simpler and less energetic and show a dominant semiannual signal near 500 $\mathrm{km}$. Finally, in the Benguela current (area 24), strong energy is found between 50 days and the semiannual period and for wavelengths from 300 to $500 \mathrm{~km}$. Part of this signal is certainly related to Agulhas eddies [Gordon and Haxby, 1990; Wakker et al., 1990].

The along-track propagation spectra for group 22 are given in Figure 8. The semiannual signal occurs only in the

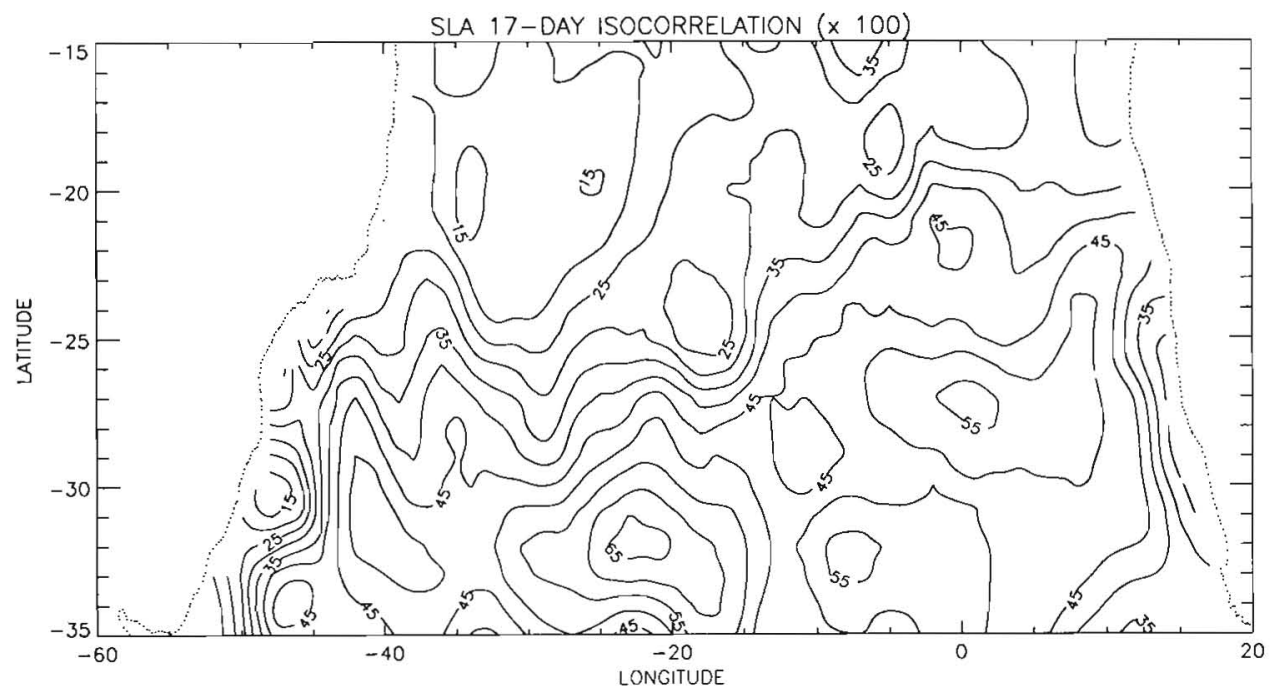

Fig. 4. The 17-day isocorrelation map $(\times 100)$ of altimetric sea level anomaly. 


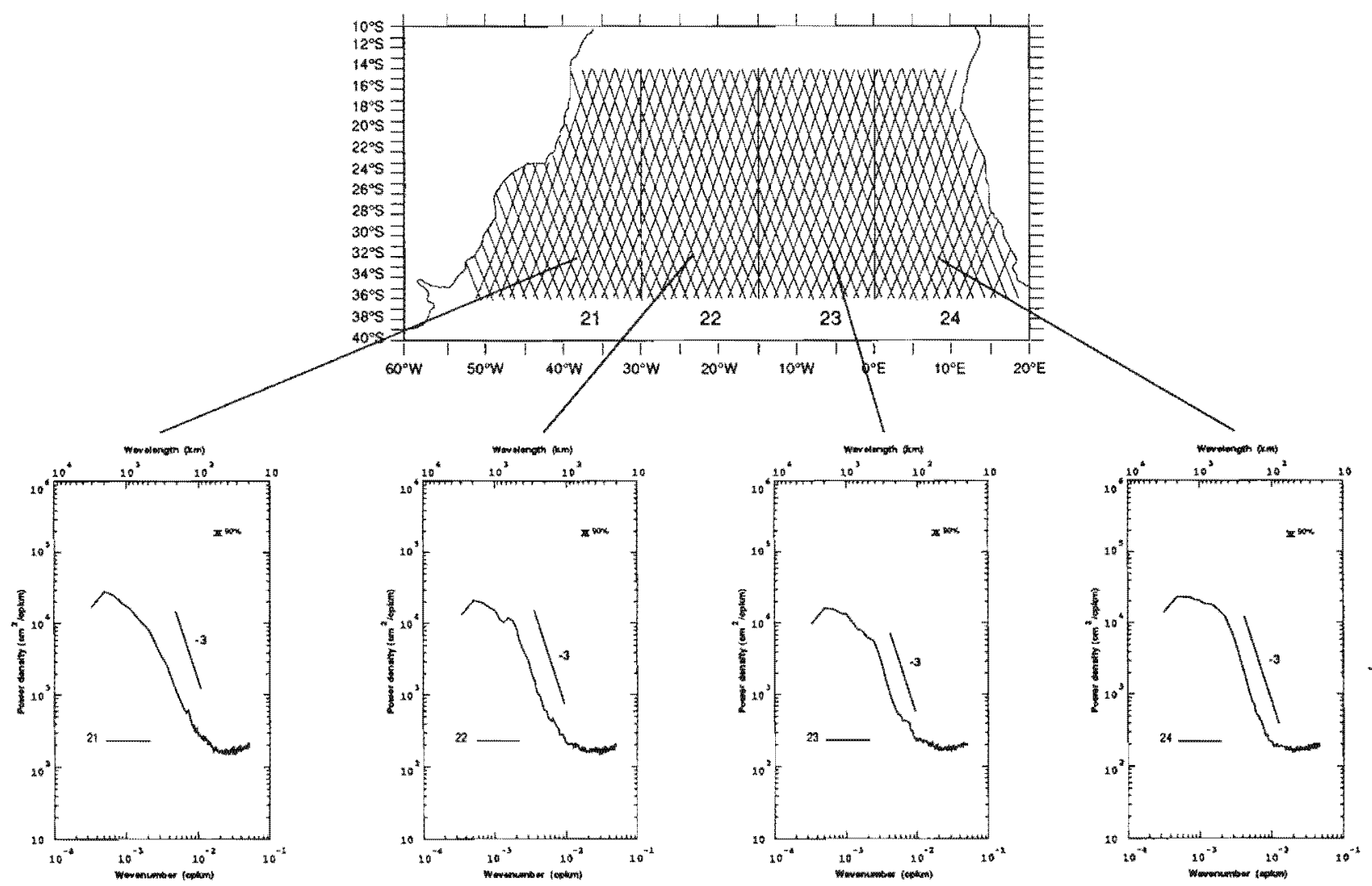

Fig. 5. Mean wavenumber spectra for groups $21,22,23$, and 24.

northwest and southwest directions, with comparable energies. This suggests that it propagates westward (or perhaps southwestward, as the energy in that direction looks slightly larger). There is also a secondary peak in the northwest direction. It is tempting to attribute the latter to Agulhas eddies [Gordon and Haxby, 1990]. Indeed, these propagate in this direction at $5-8 \mathrm{~cm} \mathrm{~s}^{-1}$ and thus should be seen at periods of the order of 100 days. The semiannual signal would then correspond to features different from these eddies.

A significant peak is found at $1500 \mathrm{~km}$ and 80 days, with a southwestward propagation. More generally, there is significant variability at high frequencies and low wavenumbers. Although the periods are somewhat too long, these signals could be related to barotropic/topographic Rossby waves.

Finally, we constructed the pseudodispersion relation by integrating the frequency-wavenumber spectrum over frequency [Le Traon, 1991]. Figure 9 shows the result for area 22. For wavelengths shorter than $600 \mathrm{~km}$ it is quasilinear with a propagation velocity of $7.7 \mathrm{~cm} \mathrm{~s}^{-1}$. A strong maximum is found near $600 \mathrm{~km}$, with an inverse dispersion relation for longer wavelengths. This maximum corresponds to the break in the wavenumber spectra and to the semiannual signal of the frequency/wavenumber spectra. This dispersion relation looks much like that for the northeast Atlantic Ocean, except that the maximum is better defined. This again indicates that the South Atlantic is more energetic than the North Atlantic gyre. The results for short wavelengths are consistent with a turbulent regime [Rhines, 1977]. For longer wavelengths the relation indicates a drastic change in dynamics from a turbulent to a linear regime. As noted above, the latter regime is probably related to propa- gation of Rossby waves. In particular, the inverse dispersion relation suggests that barotropic Rossby waves should be observed on these wavelengths as suggested by Koblinsky [1990] on the basis of an analysis of $f / H$ (the Coriolis parameter over the ocean depth).

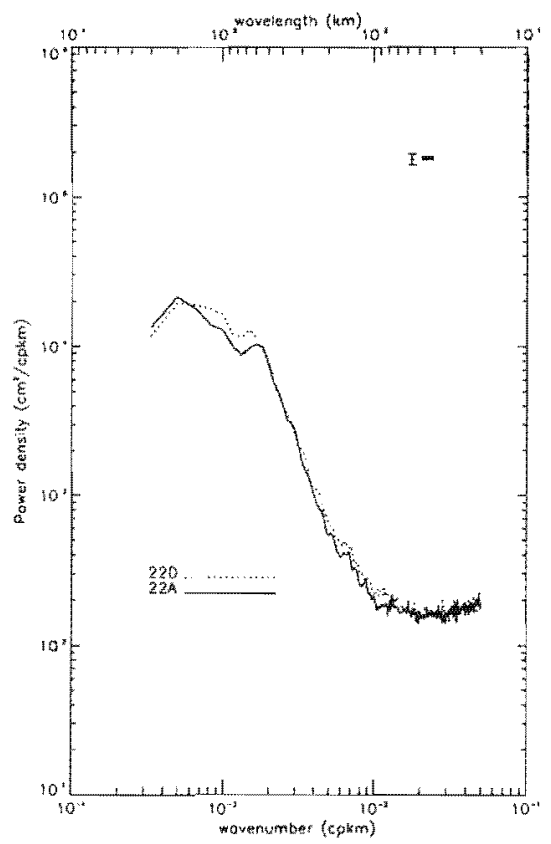

Fig. 6. Spectra of ascending (solid line) and descending (dashed line) tracks for group 22. 

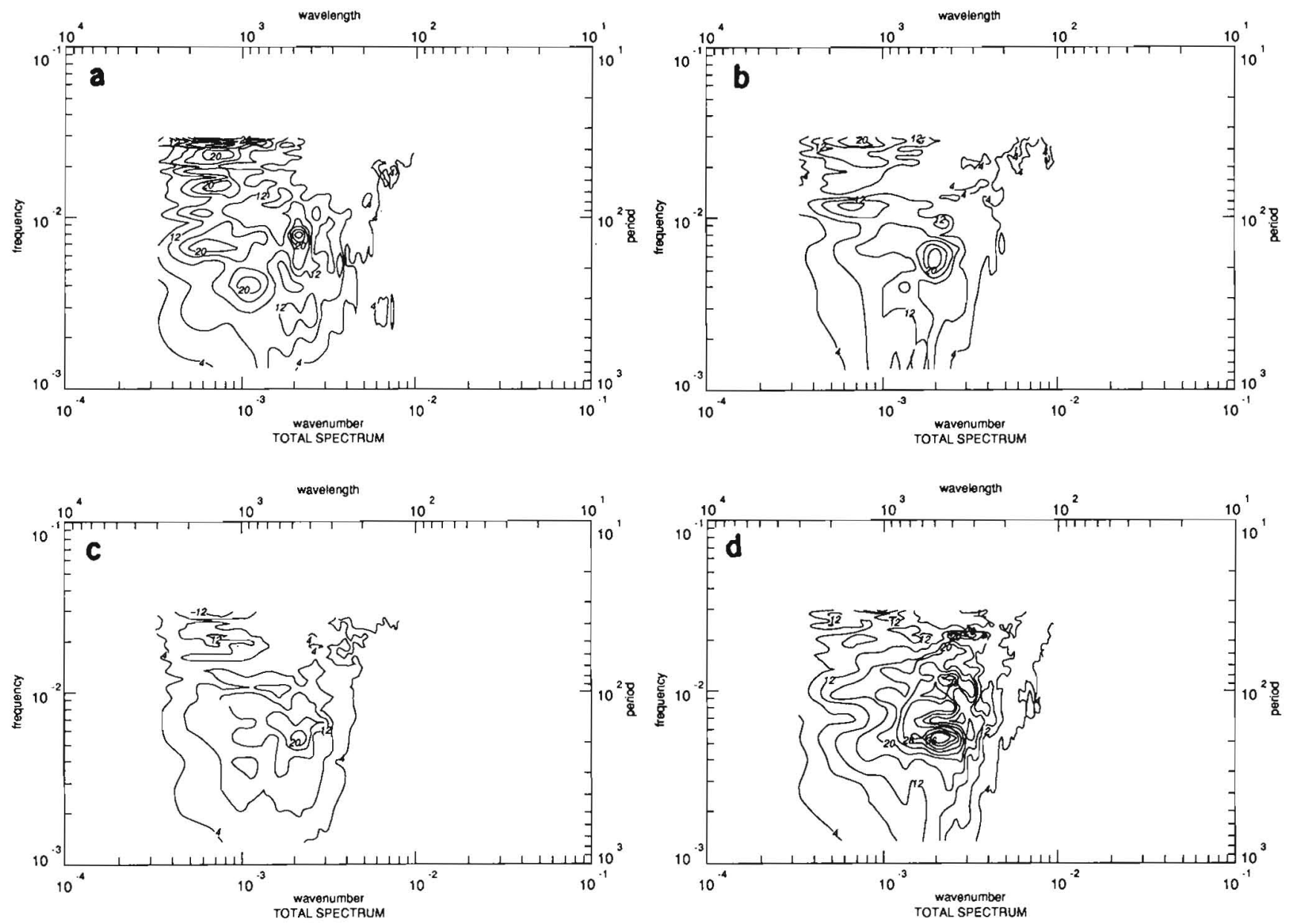

Fig. 7. Mean frequency-wavenumber spectra for group (a) $21,(b) 22,(c) 23$, and (d) 24 . Units are $\mathrm{cm}^{2}$. Contour interval is $4 \mathrm{~cm}^{2}$.

\subsection{Variations With Seasons}

All statistical properties were also calculated separately for the winter and summer seasons. Here we just give the results. The rms variability was found to be slightly larger everywhere during the northern winter (October 15 through April 15) than during summer (April 15 through October 15). It falls from 11 to $9 \mathrm{~cm}$ in the Brazil current, from 16 to $11 \mathrm{~cm}$ in the Benguela current, and from 8 to $6 \mathrm{~cm}$ in the central part, near $35^{\circ} \mathrm{S}$. The error on the seasonal rms values is typically below $10 \%$, assuming a decorrelation of one cycle over two and of along-track data over $100 \mathrm{~km}$. The differences thus seem significant. This result agrees with that of Zlotnicki et al. [1989]. In addition, we found that the 17-day isocorrelation was everywhere about $10 \%$ larger during the northern winter, i.e., when the signal is stronger. In areas 22 and 23 , along-track wavenumber spectra showed more energy for long wavelengths during the northern winter, while no significant difference could be found for the shorter wavelengths. Thus the larger variability during this season corresponds to both longer time correlations and longer wavelengths.

\section{Analysis of the Semiannual Signal}

The most striking result of the statistical study is the occurrence of a significant westward propagating semiannual signal with a wavelength of about $500 \mathrm{~km}$. There are evi- dence of semiannual ocean response in the southern hemisphere. The FGGE drifting buoys were shown to have large-scale semiannual variations in phase with the wind [Large and van Loon, 1989]. Geosat data also showed a small but significant semiannual component of large-scale variability in the Southern Ocean [Chelton et al., 1990]. Similarly, the oscillations of the Brazil/Malvinas currents confluence area are dominated by a semiannual signal [Provost and Le Traon, 1993]. Finally, semiannual Rossby waves were observed in the Indian Ocean by Park [1990] and C. Perigaud (personal communication, 1992).

In this section we perform a detailed analysis of this signal in the South Atlantic gyre. We describe how the data were processed and the results, then analyze the signal characteristics and discuss the possible excitation mechanisms.

\subsection{Data Processing}

The annual and semiannual signals and their phases were extracted from SLA data. This was done by performing a fast Fourier transform (FFT) for each 2-year time series ( 44 seventeen-day cycles) every $10 \mathrm{~km}$. If there were more than two consecutive missing cycles and the series was shorter than 1 year, the point was rejected. For each selected point and for all tracks in the area, this gives amplitudes $a_{i}$ and phases $\phi_{i}$. Phases were set relative to early November 1986.

We calculated the rms amplitude of the semiannual signal 

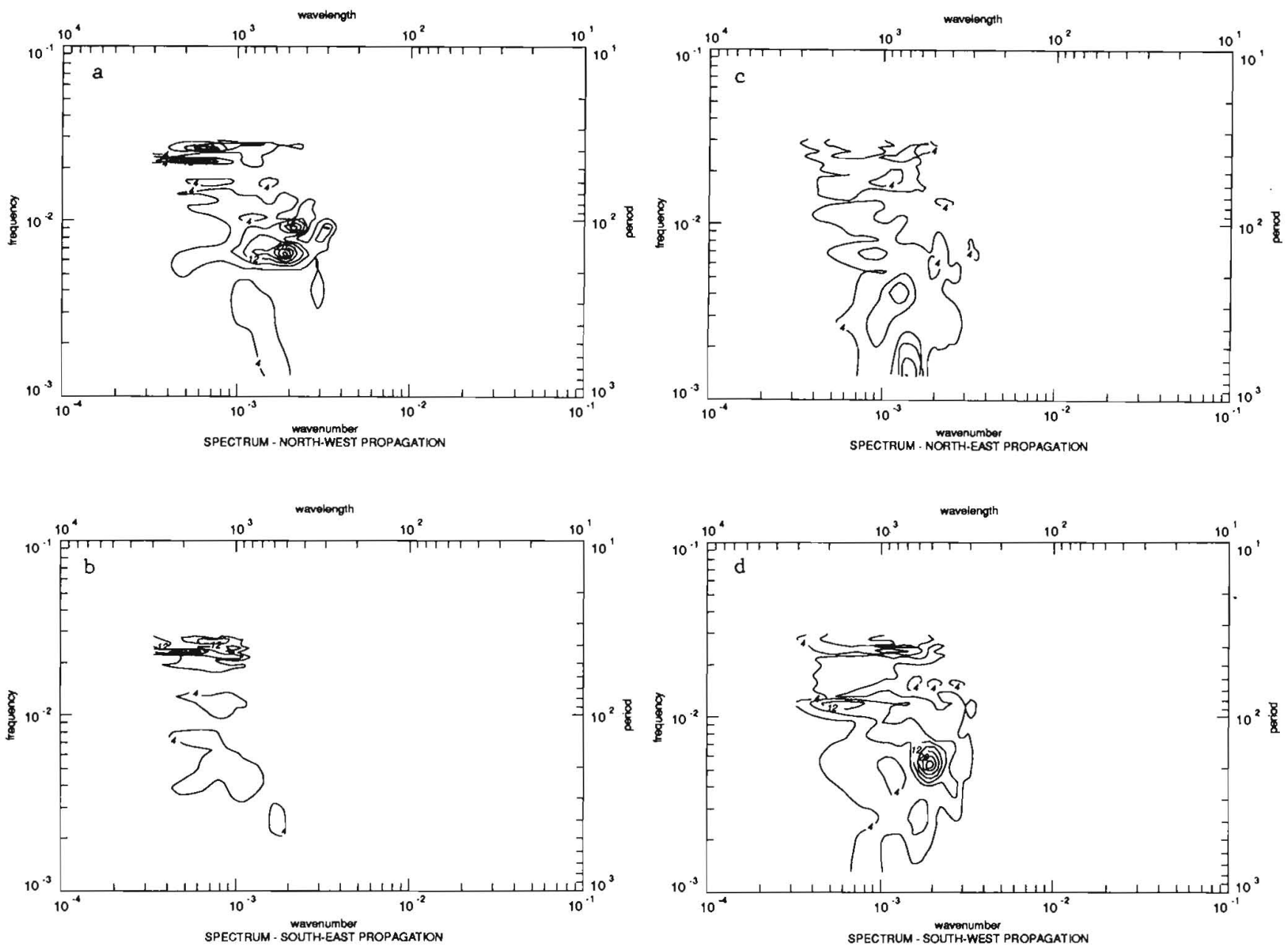

Fig. 8. Mean frequency-wavenumber spectra for group 22 for $(a)$ northwest, $(b)$ southeast, $(c)$ northeast, and $(d)$ southwest propagation. Contour interval is $4 \mathrm{~cm}^{2}$.

and the ratio of energy of the semiannual to the annual cycle in each $2^{\circ}$ latitude by $2^{\circ}$ longitude square. The semiannual signal was mapped every month for a 6 -month period, i.e., over a full cycle. This was done by calculating first the mean of $a_{i} \cos \left(2 \pi t / 6+\phi_{i}\right)$ ( $t$ is the time in months) on $0.5^{\circ}$ by $0.5^{\circ}$ squares, then applying objective analysis to the resulting values. The covariance function of the objective analysis was Gaussian, with an $e$-folding distance of $1^{\circ}$ in latitude and longitude. The noise was a priori set to $10 \%$. The noise and the squares are small enough to avoid smoothing of the signal, which has a wavelength of about $500 \mathrm{~km}$. Thus we do not give any a priori information on its spatial structure or phase velocity.

\subsection{Results}

The rms amplitude of the semiannual signal is of the order of $3 \mathrm{~cm}$ in the middle of the South Atlantic subtropical gyre (Figure 10). Higher values are found along the eastern coast of the basin, with a maximum of $8 \mathrm{~cm}$ rms near the Benguela current at $33^{\circ} \mathrm{S}-8^{\circ} \mathrm{W}$. The semiannual signal accounts for approximately $10-20 \%$ of the total variance, this relative energy being higher along the eastern coast (maximum of $24 \%$ at $33^{\circ} \mathrm{S}-8^{\circ} \mathrm{W}$ ) and along $25^{\circ} \mathrm{S}$. The semiannual signal is about twice as energetic as the annual signal there; south of $30^{\circ} \mathrm{S}$ and west of $0^{\circ} \mathrm{W}$, it is roughly half as energetic as the annual signal (not shown).

The first three semiannual signal maps at 1-month intervals are shown in Figure 11. East of the Walvis ridge, the signal is almost stationary. The amplitude reaches a maximum of $10 \mathrm{~cm}$ at $33^{\circ} \mathrm{S}-8^{\circ} \mathrm{E}$. West of $5^{\circ} \mathrm{E}$ a wave pattern appears clearly between $35^{\circ} \mathrm{S}$ and $20^{\circ} \mathrm{S}$. Crests and troughs are very coherent in space (over more than $10^{\circ}$ latitude). They are oriented along southeast to northwest lines and propagate southwestward. The wavelength is approximately $450 \mathrm{~km}$. For a semiannual wave this corresponds to a phase velocity of about $3 \mathrm{~cm} \mathrm{~s}^{-1}$. The typical amplitude is $2-3 \mathrm{~cm}$ and is maximum between $30^{\circ} \mathrm{S}$ and $25^{\circ} \mathrm{S}$. Amplitude, propagation direction, and wavelength are in agreement with frequency-wavenumber spectra. Note also the south-north orientation of the first crest at about $5^{\circ} \mathrm{E}$ for the first-month map. In the following months, when the crest propagates slowly westward, it is oriented SE-NW. This pattern explains the anisotropy of the wavenumber spectra in area 22 (Figure 6). Finally, in the west the signal gets more complex and the wave pattern disappears, probably because of features related to the boundary current or because of reflection along the boundary. This analysis was also performed for the 2 years separately. The resulting maps showed the same 


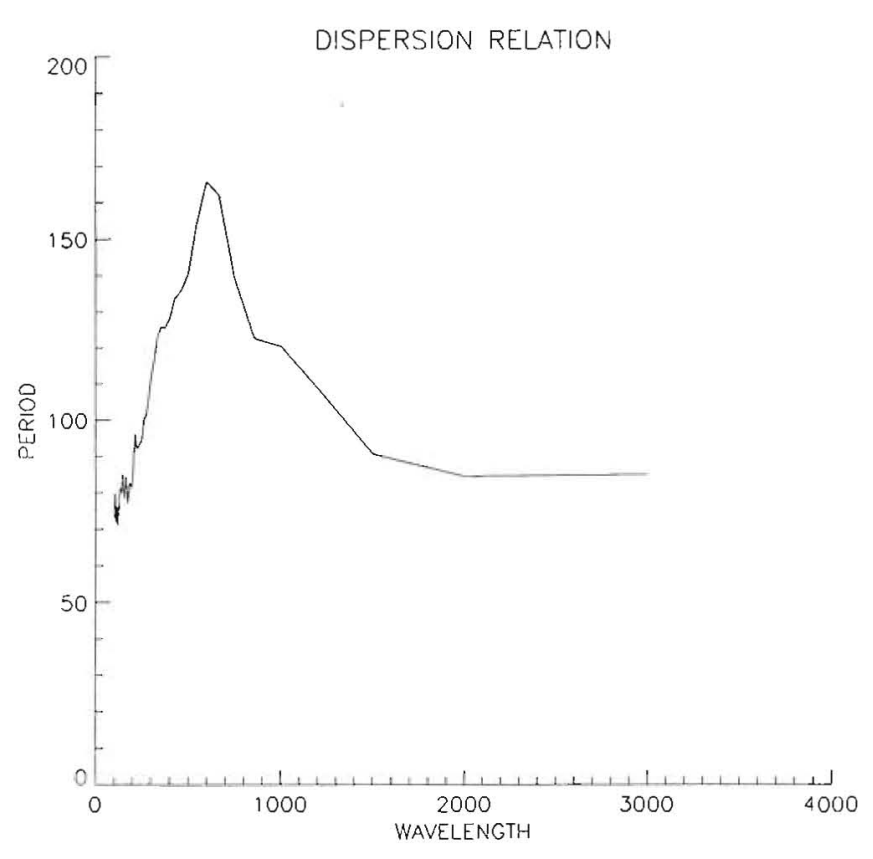

Fig. 9. Pseudodispersion relation for group 22, giving the mean period (in days) for a given wavelength (in kilometers).

characteristics with strong agreement on their phase. The most spatially coherent crests and troughs appeared to shift westward by about $800 \mathrm{~km}$ between the first and second year. This is consistent with propagation of the first-year signal at the estimated phase velocity $\left(3 \mathrm{~cm} \mathrm{~s}^{-1}\right)$. This gives us confidence in our mapping.

Recently, there has been some concern about the influence of tidal errors in annual and semiannual signals because the main tidal components are aliased at about these periods [Perigaud and Zlotnicki, 1992; Cartwright and Ray, 1990]. Given the altimeter frequency-wavenumber sampling, they can be aliased into signals with characteristics similar to Rossby waves. For example, M2 appears with an apparent period of 317 days and seems to propagate westward at 3 $\mathrm{km} / \mathrm{d}$ phase velocity. S2 and $\mathrm{K} 1$ are aliased near semiannual periods. However, the semiannual signal is particularly visible in the center of the basin, where these tidal components have an amphidromic point and thus a small amplitude. In addition, as the tidal signal is long in wavelength relative to the latitudinal size of our domain and the satellite crosses the region in less than $6 \mathrm{~min}$, a tidal error signal would be strongly correlated along the tracks and show an apparent periodic pattern in the across-track direction. As the observed wavelike pattern is oriented almost NW-SE, it is probably not a tidal error effect.

Finally, at this point, it is worth considering again the statistically stronger signal during the northern winter, as it corresponds to wavelengths larger than $500 \mathrm{~km}$. If this signal is mostly due to the semiannual slowly propagating waves, there is no particular reason for it to be stronger in winter, as any wave needs several years to cross the basin: a stronger signal in any particular season would result from interannual variations in wave amplitudes. In any case, this larger signal during the northern winter needs to be verified using several years of data.

\subsection{Comparison With Properties of Semiannual Rossby Waves}

The wavelike semiannual signal looks very much like a semiannual Rossby wave pattern. The apparent variation of phase velocity as a function of latitude agrees with the refraction of Rossby waves due to the variation of the Coriolis parameter [e.g., Schopf et al., 1981]. Using Geosat data, Park [1990] observed a semiannual signal near $40^{\circ} \mathrm{S}$ in the Crozet basin. The wavelength ranged from 300 to $600 \mathrm{~km}$ and the propagation was westward. The characteristics of our South Atlantic waves are thus very similar to those observed by Park [1990]. Finally, our observed pattern is remarkably similar to that of annual Rossby waves in the South Atlantic basin as modeled by Reason et al. [1987] (see their Figure 4). It must, however, be verified that they fit quantitatively with Rossby wave characteristics.

The dispersion relation for first-mode baroclinic Rossby waves is given by [e.g., Pedlosky, 1979]

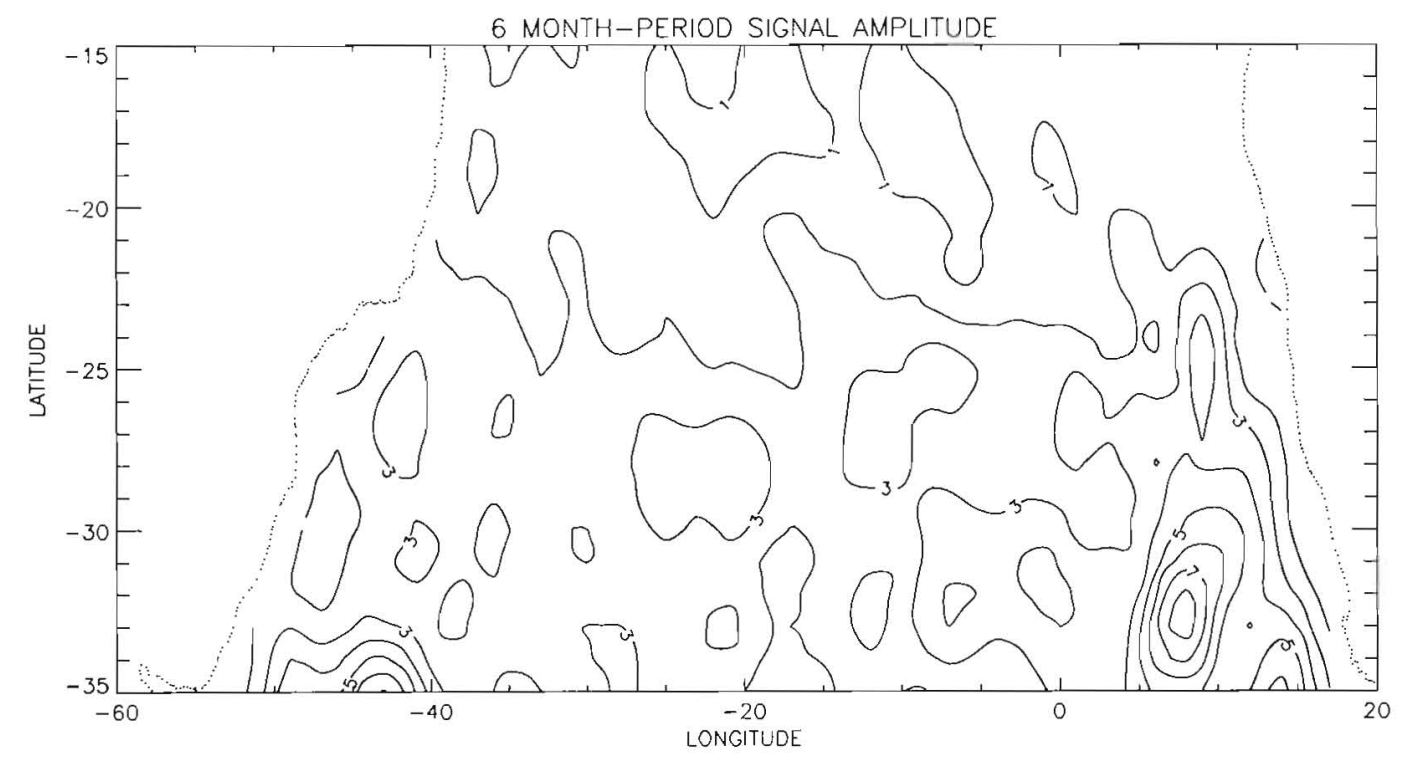

Fig. 10. Amplitude of the 6-month period signal. Contour interval is $1 \mathrm{~cm}$. 

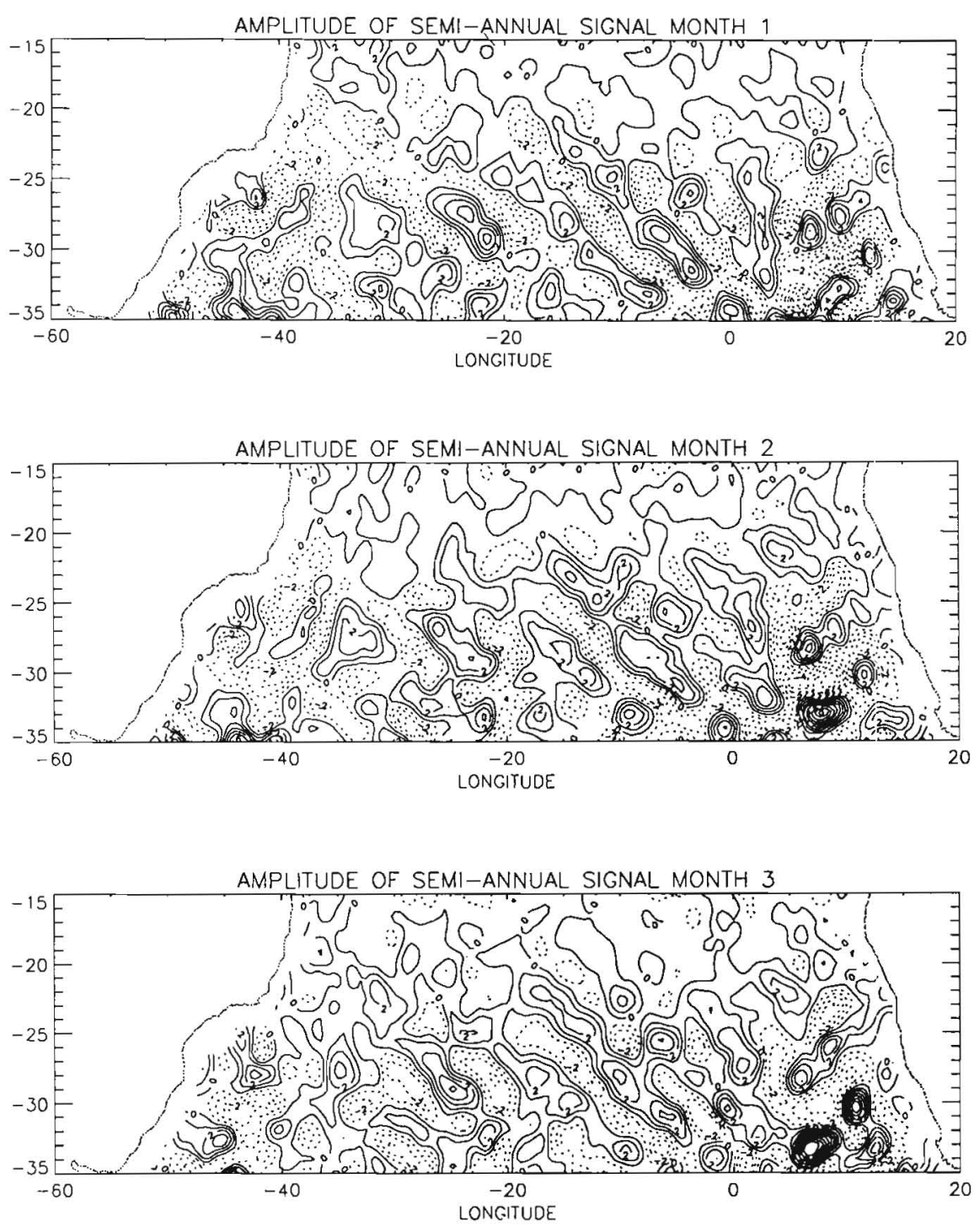

Fig. 11. Mapping of the semiannual signal at 1 -month intervals over 3 months. Contour interval is $1 \mathrm{~cm}$.

$$
w=\frac{-\beta k}{K^{2}+r i^{-2}}
$$

where $w$ is the angular frequency of the Rossby wave, $K$ its wavenumber $\left(K^{2}=k^{2}+l^{2}\right), k$ and $l$ the zonal and meridional wavenumber components, respectively, $\beta$ the meridional variation of the Coriolis parameter $f$, and $r i$ the first internal Rossby radius of deformation.

Given a mean Rossby radius of about $40 \mathrm{~km}$ between $35^{\circ} \mathrm{S}$ and $25^{\circ} \mathrm{S}$ [Houry et al., 1987], a 500-km wavelength Rossby wave with a southwestward propagation should have a period of approximately 1 year. This is what Reason et al. [1987] observed in their numerical study. The observed phase velocity is thus about twice as large as it should be. This does not take into account bathymetry and advection by the mean current. Either effect could explain the observed difference.

In the presence of a mean zonal current $U$, the Rossby wave dispersion relation (1) is modified as follows [Pedlosky, 1979]:

$$
w=\frac{k}{K^{2}+r i^{-2}}\left(U K^{2}-\beta\right)
$$

A mean zonal westward current $U(U<0)$ of $10 \mathrm{~cm} \mathrm{~s}^{-1}$ appears to be realistic for the South Atlantic subtropical gyre [Fu, 1981; Stramma and Peterson, 1989; Reid, 1989]. For the above parameters, this leads to a period of about 200 days, i.e., very close to 180 days.

The bottom topography also modifies the dispersion relation of baroclinic Rossby waves [e.g., Veronis, 1981; Barnier, 1988]. Between $35^{\circ} \mathrm{S}$ and $25^{\circ} \mathrm{S}$ the meridional slope of bottom topography is about $-1 \times 10^{-3}$ (see Figure 3 ). This means that the topographic effect is as significant as the $\beta$ effect. Although the topographic effect on baroclinic Rossby waves depends on the three-dimensional wavenumber structure [Rhines, 1977; Veronis, 1981], it can account for part of the observed differences. Note that Park [1990] also argued that the bottom topography slope was about $-1 \times 10^{-3}$ and reached the same conclusion. However, the waves do not seem to be strongly influenced by the mid-Atlantic ridge, as 
they unexplainedly cross it without any apparent change in their structure. As mean current and bottom topography both induce a larger phase velocity than is obtained by (1), we conclude that the observed wave pattern could be consistent with baroclinic Rossby waves.

\subsection{Possible Generating Mechanisms}

The observational evidence of baroclinic Rossby waves is supported by theoretical studies. In general, along with Kelvin waves, Rossby waves are the wavelike response of the ocean to any change in the balance of forces in spherical rotating shells. They can be generated at a meridional eastern boundary in response to local forcing such as local variations of the wind field along an eastern coast, northsouth fluctuations of an eastern boundary current, sudden changes in a current system, or forcing by coastal Kelvin waves [Anderson and Gill, 1975; White and Saur, 1981; Krauss and Wuebber, 1982; Mysak, 1983; Cummins et al., 1986; Reason et al., 1987; Wood and Willmott, 1988; Shriver et al., 1991]. Mid-ocean Rossby waves, remote from intense western boundary currents, can also result from direct resonant wind forcing and interaction with the topography [e.g., Lippert and Käse, 1985; Reason et al., 1987; Barnier, 1988; Hermann and Krauss, 1989].

The generation of baroclinic Rossby waves in the South Atlantic Ocean has been numerically investigated by Reason et al. [1987]. They used a linear reduced-gravity model to calculate the oceanic response to the climatological annual period of the wind stress curl [Hellerman and Rosenstein, 1983]. The model had realistic coastlines but did not include bottom topography. In the South Atlantic the response consists of annual Rossby waves with wavelengths ranging between 400 and $500 \mathrm{~km}$. Phase propagation is generally southwestward, and refraction of wave energy toward the equator is observed. The most efficient wave generators are the wind stress curl maxima off the Namibian coast $\left(25^{\circ} \mathrm{S}-\right.$ $10^{\circ} \mathrm{E}$ ), near the Agulhas plateau at $38^{\circ} \mathrm{S}-25^{\circ} \mathrm{E}$ and in the interior near $38^{\circ} \mathrm{S}-10^{\circ} \mathrm{W}$. The maximum amplitude of the interface deformation is $24 \mathrm{~m}$, which would correspond to a surface elevation of about $3-4 \mathrm{~cm}$.

As the observed Rossby waves generally have annual periods, most modeling studies have focused on the generation of annual Rossby waves. In particular, since the wind field is also known to have seasonal variations, they have often dealt with annual wind forcing. In the southern hemisphere, however, the existence of a strong semiannual wind signal is well established [van Loon and Rogers, 1984; Large and van Loon, 1989]. One may thus expect to observe oceanic semiannual Rossby waves as well. An initial poleward limit for their generation is given by the critical latitude for such waves, which is on the order of $30^{\circ} \mathrm{S}$ [Reason et al., 1987]. This means that in areas where the semiannual wind signal is the strongest (south of $30^{\circ} \mathrm{S}$ ), it cannot excite semiannual Rossby waves. This assumes that mean current and bottom topography characteristics do not significantly move the critical latitude poleward. This is probably true for the current, since it is eastward south of $35^{\circ} \mathrm{S}$ [e.g., $F u$, 1981]. On the other hand, Park [1990] found his semiannual Rossby waves at a latitude of about $40^{\circ} \mathrm{S}$, probably due to topographic effects.

In our study, waves appear to be generated along the eastern coast of South Africa. Assuming that the zonal evolution of their pattern results from wave refraction, the group velocity is directed eastward, since the first wave crest at about $5^{\circ} \mathrm{E}$ has a meridional axis. This means that the generation area is east of $5^{\circ} \mathrm{E}$ between latitudes $25^{\circ} \mathrm{S}$ and $30^{\circ} \mathrm{S}$. Otherwise, if the southwestward propagation does not result from wave refraction, this would imply a group velocity directed northwestward and a generation area further south, probably near the Agulhas current. This would require a high critical latitude of semiannual Rossby waves.

The most plausible generation area is thus east of $5^{\circ} \mathrm{E}$ between latitudes $25^{\circ} \mathrm{S}$ and $30^{\circ} \mathrm{S}$. This is also where the semiannual signal is the strongest. Note that this is one of the generation areas found by Reason et al. [1987]. The waves may be excited by a local maximum of the second harmonic of the wind field and/or the Benguela current. To decide whether this is true, a detailed analysis of simultaneous winds in the South Atlantic would be needed. For the time being, this is difficult because the semiannual wind component is not very well represented in Atmospheric Global Circulation Models [e.g., Meehl, 1991]. However, the maximum of the semiannual signal near $5^{\circ} \mathrm{E}$ is reached in November, in phase with the climatological wind signal [van Loon and Rogers, 1984]. Appendix B shows that the largescale variability signal as extracted by Wunsch [1991 $a$ ] also has a significant semiannual signal in phase with the wind signal.

\section{Conclusions}

Using 2 years of Geosat altimeter data, we extensively analyzed the mesoscale statistical properties in the South Atlantic gyre, between $15^{\circ} \mathrm{S}$ and $35^{\circ} \mathrm{S}$. In agreement with former studies, the signal is more energetic along the western and eastern boundaries, while variability inside the gyre increases southward from 3-7 cm rms. Along-track wavenumber spectra are comparable for ascending and descending tracks, with slopes of -3 to -4 for wavelengths between 100 and $500-700 \mathrm{~km}$. Such nonlinear turbulent regimes are found $10^{\circ}$ closer to the equator than in the North Atlantic. For longer wavelengths, a smaller slope is found, consistent with linear dynamics. The mesoscale signal is still strongly correlated after 17 days (more than $40 \%$ correlation) in the middle of the gyre, while its variation is faster in energetic areas (less than $20 \%$ correlation after 17 days).

Frequency/wavenumber spectra show little annual signal but reveal an important semiannual signal near $500-\mathrm{km}$ wavelength. This corresponds to a strong peak in the pseudodispersion relation. The relation is dispersive for longer wavelengths, consistently with propagation of Rossby waves.

We mapped the semiannual signal. It is stationary in the east of the basin, but in the middle of the gyre consists of wavelike features of 2- to $3-\mathrm{cm}$ amplitude propagating westward at $3 \mathrm{~cm} \mathrm{~s}^{-1}$. This wave pattern is north-south near $5^{\circ} \mathrm{E}$, i.e., close to the Walvis ridge, but gets refracted and propagates southwestward near $30^{\circ} \mathrm{W}$. This phase velocity may be consistent with that of semiannual Rossby waves if one takes into account mean current and/or bathymetry effects. This wave pattern is very similar to that of annual Rossby waves as modeled by Reason et al. [1987] in the same area.

These semiannual Rossby waves could be excited by the semiannual wind component near $5^{\circ} \mathrm{E}$, and/or by interaction 
of semiannual variations of the Benguela current with the Walvis ridge. There, the semiannual signal is in phase with climatological winds, as analyzed by van Loon and Rogers [1984].

Dynamical modeling would provide a better interpretation of this semiannual signal. The model should include realistic bathymetry and coastlines, including the open boundary with the Indian Ocean. Modeling would also be helpful for studying the reflection properties of the observed waves at the western boundary and the influence of bottom topography [e.g., Barnier, 1988]. The wind forcing should also be realistic, at least with regard to its annual and semiannual components. The model should be able to reproduce the gyre circulation. More generally, the semiannual response of the South Atlantic subtropical gyre can be a test for dynamical models of the circulation in this area.

\section{APPENDIX A}

We processed the data and tested our techniques as described in Le Traon et al. [1990] and Le Traon [1991]. We used the Geophysical Data Records (GDR's) [Cheney et al., 1987], except for the more precise orbit calculated by Haines et al. [1990]. We did not use the T2-GDR's [Cheney et al., 1991], as they were not yet available. We applied the geophysical corrections from the GDR's, plus an electromagnetic bias correction calculated as $2 \%$ of significant wave height. Anomalous values were eliminated following the now classic criteria. Data coverage is quite good in this area: for descending tracks, it is almost complete for the first year (22 cycles) and only slightly degraded for the second year (more than 15 cycles). More ascending tracks are missing, especially near the western boundary (less than 12 cycles per year).

To extract the altimetric mesoscale signal, we used the conventional along-track technique; by comparison with the work of Le Traon et al. [1990], we analyzed longer arcs of $3000-\mathrm{km}$ length. Given the $45 \mathrm{~cm}$ rms precision of the GEM-T2 orbit, the 1 cycle/revolution residual orbit error is well described by a straight line [Tai, 1989, 1991].

Sea level anomalies (SLA's), i.e., the differences between the detrended individual profiles and the mean arcs, were filtered along-track using a $100-\mathrm{km}$ cutoff wavelength Lanczos filter. SLA isocorrelation at 17 days was derived from the temporal covariances at each point (every $10 \mathrm{~km}$ ). Maps were then produced for the rms SLA, for variance of the mesoscale geostrophic velocity and for the 17-day isocorrelation by objective analysis (Gaussian spatial autocorrelation with $e$-folding of $2^{\circ}$ in latitude and longitude).

We then grouped the data into four domains of about $15^{\circ}$ in longitude (Figure 1). There were about 22 tracks per group, but on average, half of them were too gappy for frequency/ wavenumber spectral calculation. Along-track statistical properties were calculated separately for all tracks and averaged for each group. Data were not filtered along-track before these calculations. For wavenumber spectra, separate averages were also calculated for ascending and descending tracks, as well as for the summer and winter seasons. Confidence intervals were estimated assuming that one in every three consecutive cycles and one in every three adjacent tracks were independent. Frequency/wavenumber spectra were estimated by two-dimensional FFT. They were either calculated as total spectra, or separately for each direction, corresponding to apparent along-track propagations (southeastward and northwestward for ascending tracks, southwestward and northeastward for descending tracks).

\section{APPENDix B}

The semiannual variability of the Benguela current could be related to a similar effect in the whole South Atlantic gyre. In order to examine whether the latter also presents a semiannual signal, we analyzed the Geosat large-scale variability signal of the area, as extracted by Wunsch [1991a]. The signal is extracted as follows.

The initial data were the same as for mesoscale studies, except that they are not corrected for tropospheric and ionospheric propagation effects. The orbit error was reduced by filtering the periodic signal out of the 6-day orbit arcs, at six frequencies close to 1 cycle/revolution, 2 cycles/ revolution, and 4 cycles/revolution. This did not remove all of the orbit error. The data were averaged along-track for 20 $s$ and completed over land by the GEM-T2 geoid [Marsh et al., 1989]. They were then split into 3.4-day groups, and each group was expanded into spherical harmonics over the globe, up to degree and order 18 , as though the data were contemporaneous. This resulted in time series of the spherical harmonic coefficients. Variability maps were constructed from the differences between each map and the mean of these developments. Finally, these altimetric variability maps were complemented by data from 34 tide gauge time series, all longer than 2 years. These were attributed a variance of $100 \mathrm{~cm}^{2}$. This processing also provides formal error maps of the estimates. In the South Atlantic gyre and most other places it is less than $4.5 \mathrm{~cm}$ rms. It is not known quantitatively how much residual orbit error or aliased geoid signal is still contained in these maps. In general, they seem to have too much energy. Note that this type of processing aliases errors in the tidal corrections into periods much shorter than annual and semiannual (L. Fu, personal communication, 1992).

Time series for the first 2 years of the Geosat exact repeat mission were extracted in the middle of each of the four domains, at $25^{\circ} \mathrm{S}$ and $40^{\circ} \mathrm{W}, 22.5^{\circ} \mathrm{W}, 7.5^{\circ} \mathrm{W}$ and $10^{\circ} \mathrm{E}$, respectively. The original series are rather noisy $(2 \sigma$ : about $50 \mathrm{~cm})$ with spurious points larger than $1 \mathrm{~m}$ at the end of the period. This likely results from residual orbit error. Data exceeding the 2- $\sigma$ level were thus discarded. In addition, during the 2-year period the time series have systematic drift of about $15-\mathrm{cm}$ amplitude, which was suppressed by linear regression. Finally, the data were monthly averaged. The resulting time series for area 23 is shown in Figure 12.

The amplitudes and phases of the annual and semiannual components were calculated by least squares regression, first for each year separately. In the Brazil current (area 21) the amplitudes of the annual signals differ by as much as $50 \%$ between the 2 years, but their phases, as well as the amplitudes and phases of the semiannual signals, are similar. In the center of the domain (areas 22 and 23) the signals are very consistent between the 2 years. In the east (area 24) they are very small and not robust.

We then processed the 2-years' data. We verified that the results were insensitive to the preliminary processing of the time series (data elimination, detrending, and monthly averaging). The interannual consistency, a weaker influence of 


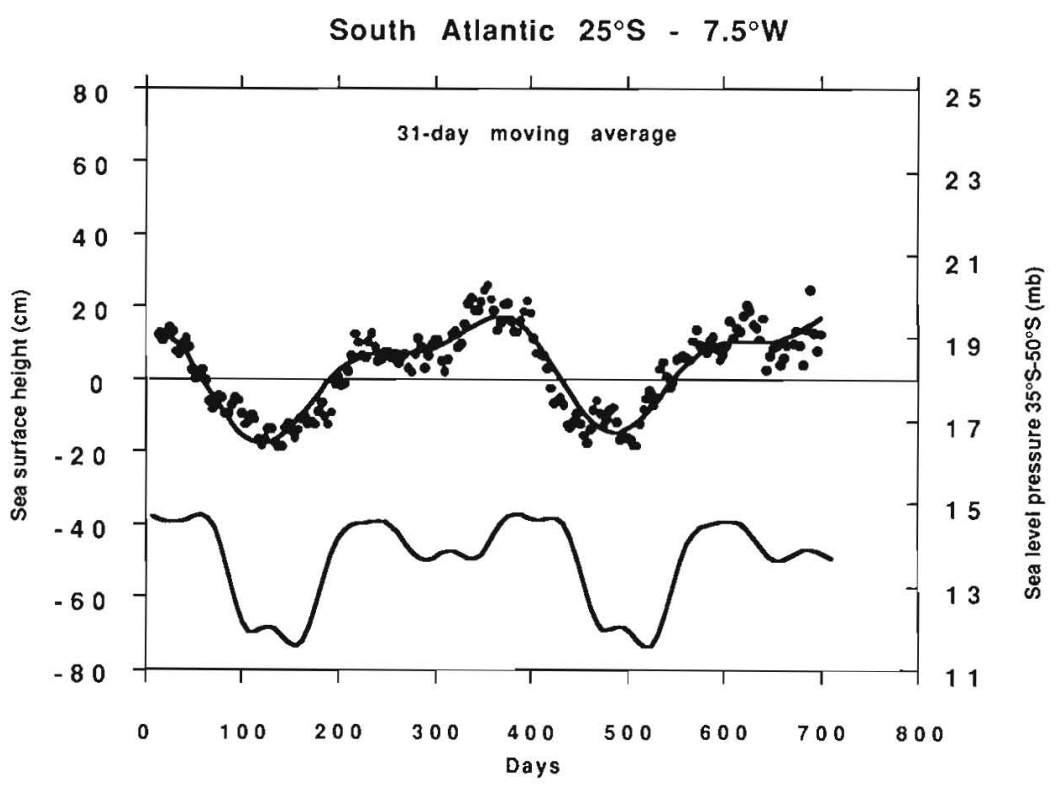

Fig. 12. Time series of the large-scale variability signal at $25^{\circ} \mathrm{S}-7.5^{\circ} \mathrm{W}$ (centimeters; scale on the left). The values (dots) are calculated every 3.4 days and are monthly averaged. The line is the least squares fit to an annual plus a semiannual component. The bottom curve represents the zonally averaged sea level pressure difference between $35^{\circ} \mathrm{S}$ and $50^{\circ} \mathrm{S}$ (millibars; scale on the right); it was replotted from Figure 6 of van Loon and Rogers [1984] and is shown for visual comparison only.

the coasts, and a less severe effect of mesoscale variability should make the results more significant at the center of the gyre. There the annual signal is dominant (13- to $15-\mathrm{cm}$ amplitude; $65-80 \%$ of the variance). The semiannual signal is also significant, with an amplitude of about $6 \mathrm{~cm}(12-19 \%$ of the total variance). These two terms thus explain $85-90 \%$ of the total signal! The maximum amplitude of the annual signal is reached 310 days after November 1986, at the end of the northern summer. That of the semiannual signal is reached 12-24 days after November 1986.

Large and van Loon [1989] found that, in the South Atlantic gyre, the first and second harmonics of the 1979 monthly mean zonal buoy drifts contributed $60-87 \%$ of their total annual variance and that the first maximum of the second harmonic occurred in May-June. Climatological winds present a northern summer maximum, and their semiannual component reaches its first maximum in June [van Loon and Rogers, 1984]. This is depicted in Figure 12, which shows their zonally averaged climatological sea level pressure difference between $35^{\circ} \mathrm{S}$ and $50^{\circ} \mathrm{S}$ (their equatorward signal is in phase with this one). Furthermore, the amplitude of their semiannual wind component is higher west of the Walvis ridge. Thus the two estimations of the large-scale oceanic signals are in phase with each other and with the climatological wind forcing.

This coincidence suggests that the large-scale altimetric signal is not simply a noise or a residual orbit error. This result seems to confirm the finding of Wunsch [1991b] that, at large scales, the ocean responds quite directly to the large-scale variations of wind forcing.

Acknowledgments. We thank C. Brossier for his efficient management of the Geosat data. Discussions with B. Barnier, X. Carton, P. Gaspar, C. Provost, and P. Vincent have been very helpful. C. Wunsch kindly made available his time series and reviewed the manuscript. We also thank one of the reviewers for his constructive criticisms. This work was supported by a GREOS contract.

\section{REFERENCES}

Anderson, D. L. T., and A. E. Gill, Spin-up of a stratified ocean with applications to upwelling, Deep Sea Res., 22, 683-696, 1975.

Barnier, B., A numerical study of the influence of the Mid-Atlantic Ridge on nonlinear first-mode baroclinic Rossby waves generated by seasonal winds, J. Phys. Oceanogr., 18, 417-433, 1988.

Cartwright, D. E., and R. D. Ray, Oceanic tides from Geosat altimetry, J. Geophys. Res., 95, 3069-3090, 1990.

Chelton, D. B., M. G. Schlax, D. L. Witter, and J. G. Richman, Geosat altimeter observations of the surface circulation of the southern ocean, J. Geophys. Res., 95, 17,877-17,904, 1990.

Cheney, R. E., B. C. Douglas, R. W. Agreen, L. Miller, D. L. Porter, and N. S. Doyle, Geosat altimeter geophysical data records user handbook, Tech. Memo NOS NGS-46, 56 pp., Natl. Ocean Serv., Rockville, Md., 1987.

Cheney, R. E., W. J. Emery, B. J. Haines, and F. Wentz, Recent improvements in Geosat altimeter data, Eos Trans. AGU, 72 , $577-580,1991$.

Cummins, P. F., L. A. Mysak, and K. Hamilton, Generation of annual Rossby waves in the North Pacific by the wind stress curl, J. Phys. Oceanogr., 16, 1179-1189, 1986.

Daniault, N., and Y. Menard, Eddy kinetic energy distribution in the southern ocean from altimetry and FGGE drifting buoys, $J$. Geophys. Res., 90, 11,877-11,899, 1985.

De Mey, P., and Y. Ménard, Synoptic analysis and dynamical adjustment of Geos 3 and Seasat altimeter eddy fields in the northwest Atlantic, J. Geophys. Res., 94, 6221-6230, 1989.

Fu, L. L., The general circulation and meridional heat transport of the subtropical South Atlantic determined by inverse methods, $J$. Phys. Oceanogr., 11, 1171-1193, 1981.

Fu, L. L., and V. Zlotnicki, Observing oceanic mesoscale eddies from Geosat altimetry: Preliminary results, Geophys. Res. Lett. I6, 457-460, 1989.

Gordon, A. L., and W. F. Haxby, Agulhas eddies invade the South Atlantic: Evidence from Geosat altimeter and shipboard conductivity temperature-depth survey, J. Geophys. Res., 95, 3117-3125, 1990.

Haines, B. J., G. H. Born, G. W. Rosborough, J. G. Marsh, and 
R. G. Williamson, Precise orbit computation for the Geosat exact repeat mission, J. Geophys. Res., 95, 2871-2886, 1990.

Hellerman, S., and M. Rosenstein, Normal monthly wind stress over the world ocean with error estimates, J. Phys. Oceanogr., 13, 1093-1104, 1983.

Hermann, P., and W. Krauss, Generation and propagation of annual Rossby waves in the North Atlantic, J. Phys. Oceanogr., 19, 727-744, 1989

Houry, S., E. Dombrowsky, P. De Mey, and J-F. Minster, BruntVäisälä frequency and Rossby radii in the south Atlantic, J. Phys. Oceanogr., 17, 1619-1626, 1987.

Koblinsky, C. J., The global distribution of $\mathrm{f} / \mathrm{H}$ and the barotropic response of the ocean, J. Geophys. Res., 95, 3213-3218, 1990.

Krauss, W., and C. Wuebber, Response of the North Atlantic to annual wind variations along the eastern coast, Deep Sea Res. $29,851-868,1982$.

Large, W. G., and $H$. van Loon, Large scale, low frequency variability of the 1979 FGGE surface buoy drifts and winds over the southern hemisphere, J. Phys. Oceanogr., 19, 216-232, 1989.

Le Traon, P. Y., Time scales of mesoscale variability and their relationship with spatial scales in the North Atlantic, J. Mar. Res., 49, 467-492, 1991.

Le Traon, P. Y., M. C. Rouquet, and C. Boissier, Spatial scales of mesoscale variability in the North Atlantic as deduced from Geosat data, J. Geophys. Res., 95, 20,267-20,286, 1990.

Lippert, A., and R. H. Käse, Stochastic wind forcing of baroclinic Rossby waves in the presence of a meridional boundary, J. Phys. Oceanogr., 15, 185-194, 1985.

Marsh, J. G., et al., The GEM-T2 gravitational model, NASA Tech. Memo., TM 100746, 94 pp., 1989.

Meehl, G. A., A reexamination of the semi-annual oscillation in the southern hemisphere, J. Climate, 4, 911-926, 1991.

Minster, J.-F., D. Jourdan, E. Normant, C. Brossier, and M.-C. Gennero, An improved special sensor microwave imager water vapor correction for Geosat altimeter data, J. Geophys. Res., 99, 17,859-17,872, 1992.

Mysak, L. A., Generation of annual Rossby waves in the North Pacific, J. Phys. Oceanogr., 13, 1910-1923, 1983.

Park, Y. H., Mise en évidence d'ondes planétaires semi-annuelles dans le sud de l'océan Indien par altimétrie satellitaire, $C . R$. Acad. Sci. Paris, 310, 919-926, 1990.

Paterson, S. L., Surface circulation and kinetic energy distributions in the southern hemisphere from FGGE drifting buoys, J. Phys. Oceanogr., 15, 865-884, 1985.

Pedlosky, J., Geophysical Fluid Dynamics, 624 pp., Springer Verlag, New York, 1979.

Perigaud, C., and V. Zlotnicki, Importance of Geosat orbit and tidal corrections for large scale Indian Ocean variations, Oceanol. Acta, 15, 491-505, 1992.

Piola, A. R., H. A. Figueroa, and A. A. Bianchi, Some aspects of the surface circulation south of $20^{\circ} \mathrm{S}$ revealed by first GARP global experiment drifters, J. Geophys. Res., 92, 5101-5114, 1987.

Provost, C., and P. Y. Le Traon, Spatial and temporal scales in altimetric variability in the Brazil-Malvinas current Confluence region: Evidence of anisotropy, dominance of the semiannual period and large scales, J. Geophys. Res, in press, 1993.

Reason, C. J. C., L. A. Mysak, and P. F. Cummins, Generation of annual-period Rossby waves in the south Atlantic Ocean by the wind-stress curl, J. Phys. Oceanogr., 17, 2030-2042, 1987.

Reid, J., On the total geostrophic circulation of the South Atlantic
Ocean: Flow patterns, tracers, and transports, Progr. Oceanogr., 23, 149-244, 1989.

Rhines, P. B., The dynamics of unsteady currents, in The Sea, vol. 6, Marine Modelling, edited by E. D. Goldberg, et al., pp. 189-318, John Wiley, New York, 1977.

Sandwell, D. T., and B. Zhang, Global mesoscale variability from the Geosat exact repeat mission: Correlation with ocean depth, $J$. Geophys. Res., 94, 17,971-17,984, 1989.

Schopf, P. S., D. L. T. Anderson, and R. Smith, Beta-dispersion of low-frequency Rossby waves, Dyn. Atmos. Oceans, 5, 187-214, 1981.

Shriver, J. F., M. A. Johnson, and J. J. O'Brien, Analysis of remotely forced oceanic Rossby waves off California, J. Geophys. Res., 96, 749-757, 199I.

Stammer, D., and C. W. Böning, Mesoscale variability in the Atlantic Ocean from Geosat altimetry and Woce high resolution numerical modelling, J. Phys. Oceanogr., 22, 732-752, 1992.

Stramma, L., and R. G. Peterson, Geostrophic transport in the Benguela current region, J. Phys. Oceanogr., 19, 1440-1448, 1989.

Tai, C. K., Accuracy assessment of widely used orbit error approximations in satellite altimetry, J. Atmos. Oceanic Technol., 6, $147-150,1989$.

Tai, C. K., How to observe the gyre to global-scale variability in satellite altimetry: Signal attenuation by orbit error removal, $J$. Atmos. Oceanic Technol., 8, 271-288, 1991.

van Loon, H., and J. C. Rogers, Interannual variations in the half-yearly cycle of pressure gradients and zonal wind at sea level on the southern hemisphere, Tellus, 36, 76-86, 1984.

Veronis, G., Dynamics of large-scale ocean circulation, in Evolution of Physical Oceanography, edited by B. A. Warren and C. Wunsch, pp. 140-183, MIT Press, Cambridge, Mass., 1981.

Wakker, K. F., R. C. A. Zandbergen, M. C. Naeije, and B. A. C. Ambrosius, Geosat altimeter data analysis for the oceans around South Africa, J. Geophys. Res., 95, 2991-3006, 1990.

White, W. B., and J. F. T. Saur, A source of annual baroclinic waves in the subtropical north Pacific, J. Phys. Oceanogr., II, $1452-1462,1981$.

Wood, R. G., and A. J. Willmott, The generation of baroclinic Rossby waves by stationary and translating currents, Part 1, Stationary currents, Geophys. Astrophys. Fluid Dyn., 41, 287$311,1988$.

Wunsch, C., Global-scale sea surface variability from combined altimetric and tide gauge measurements, J. Geophys. Res., 96, 15,053-15,082, $1991 a$.

Wunsch, C., Large-scale response of the ocean to atmospheric forcing at low frequencies, J. Geophys. Res., 96, 15,083-15,092, $1991 b$.

Zlotnicki, V., L. L. Fu, and W. Patzert, Seasonal variability in global sea level observed with Geosat altimetry, J. Geophys. Res., 94, 17,959-17,969, 1989.

P.-Y. Le Traon, Collecte Localisation Satellites, 18, Avenue Edouard-Belin, 31055 Toulouse Cedex, France.

J.-F. Minster, UMR39/GRGS, 18, Avenue Edouard-Belin, 31055 Toulouse Cedex, France.

(Received August 14, 1992 ; revised December 7, 1992; accepted January 11, 1993.) 